\title{
LITERATURA INFANTOJUVENIL E MÚSICA: REPRESENTAÇÃO DA CRIANÇA NEGRA E ABORDAGENS DA ALTERIDADE NA FRANÇA E NO BRASIL
}

Véronique Francisi

Valéria Barbosa ${ }^{\mathrm{ii}}$

\begin{abstract}
RESUMO: A literatura infanto-juvenil é um objeto cultural da criança, mas também um material pedagógico muito presente nas escolas, nas famílias e nos outros espaços de socialização da infância. Esse artigo examina os livros infanto-juvenis ilustrados, cujo personagem principal é a criança negra, e que tenha a música como temática, a partir de dois estudos realizados na França e no Brasil. O objetivo é de observar a representação da criança negra e as abordagens da alteridade mediante análise de conteúdo. Nesses dois contextos, os livros são frequentemente objetos híbridos: um documento em papel, texto, imagem e som, um suporte pedagógico, artístico e identitário. Os resultados revelam que as referências e abordagens da alteridade são às vezes diferentes: na França, as imagens de crianças negras são inscritas nos territórios da África mitificada e da América segregacionista; no Brasil elas são associadas ao tema da identidade racial. Porem, seja no contexto francês ou brasileiro, podemos notar que diferentes limites aparecem e examiná-los supõe levar em conta a questão da interseccionalidade situada aqui em torno das relações sociais de classe, raça e gênero.
\end{abstract}

Palavras-chave: Literatura Infantojuvenil; Criança Negra; Música; Alteridade; Brasil, França.

\section{CHILDREN AND YOUTH LITERATURE AND MUSIC: REPRESENTATION OF THE BLACK CHILD AND APPROACHES OF OTHERNESS IN FRANCE AND BRAZIL}

\begin{abstract}
Children's literature is a cultural matter for children but it is also a pedagogical tool, very present in schools, families and other spaces where children socialize. This article examines illustrated children's books that present the black child as their main character and the music as their main topic. This analysis comes from two studies conducted in France and Brazil. The objective is to observe the portrayal of the black child and the different approaches for otherness through content analysis. In both contexts the work is often a hybrid object: a document on paper, a text, an image and a sound; a pedagogical tool that also serves as an artistic support and one that asserts identity. The results show that the references and approaches of otherness sometimes differ: In France, the images of the black child refer to the mystified Africa or the segregationist America, while in Brazil they are associated with racial identity. However, whatever the context, whether it is the French or the Brazilian one, different challenges are turning up and analyzing them implies considering the question of intersectionality around socioeconomic, racial and gender matters.
\end{abstract}

Key-words: Children and youth literature; Black Child ; Music ; Otherness ; Brazil ; France.

2020 Bargas; Ayoub; Assaritti, Scarazzatto, Assis. Este é um artigo de acesso aberto distribuído sob os termos da Licença Creative Commons Atribuição Não ComercialCompartilha Igual (CC BY-NC-4.0), que permite uso, distribuição e reprodução para fins não comerciais, com a citação dos autores e da fonte original e sob a mesma licença 


\section{INTRODUÇÃO}

Os estudos sobre a literatura infantojuvenil mostram que um dos seus objetivos é acompanhar a descoberta do mundo e da alteridade, de si mesmo e dos outros (PRINCE, 2010). Os livros ilustrados fazem parte do material educativo muito presente nas escolas, em instituições recreativas e nas famílias. A partir do trabalho pioneiro de Belotti (1974), diversos autores enfatizaram a questão dos arquétipos e estereótipos que os livros transmitem sobre as representações de gênero (BRUGEILLES; CROMER; CROMER, 2002; BRUGEILLES; CROMER, 2005; CHABROL-GAGNE, 2011). Mais recentemente, as representações étnicoraciais foram exploradas observando as imagens e representações da criança negra na literatura infantojuvenil (FRANCIS; BARBOSA et al, 2018; 2019; FRANCIS, 2015; 2016, THIERY; FRANCIS, 2013; BARBOSA, 2015a 2015b; BARBOSA; SIROTA, 2016). Este artigo enfoca mais especificamente os livros infantojuvenis que contém a música como temática, a partir de dois estudos realizados na França e no Brasil ${ }^{1}$. O corpus consiste em títulos selecionados a partir de um critério central: a presença de um personagem que seja criança e negro, destacando a questão melânica fato da natureza, cuja interpretação foi e continua sendo um fato cultural (NDIAYE, 2006, p.39).

$\mathrm{Na}$ França, as coleções literárias com música, propostas pelas editoras mais populares, fazem parte de uma política de tiragem em série, destinada a diferentes faixas etárias. A produção, diversificada e adaptada a públicos variados, explica a orientação de diversas coleções sobre os patrimônios musicais franceses e de outros países, destacando referências culturais múltiplas e plurais (FRANCIS, 2016), incluindo o universo da música negra (RAIBAUB, 2010).

No Brasil, as editoras se dedicam a responder às demandas das políticas públicas educacionais de 2003 e 2004 pela "educação étnico-racial" que foram implementadas, exigindo obrigatoriamente a inclusão de personagens negros, bem como de outros grupos étnico-raciais no material educativo (BRASIL, 2005, p.24). Após a adoção dessas políticas, as editoras

\footnotetext{
${ }^{1}$ Esses dois estudos foram apresentados no Colóquio da Associação Francesa de Educação Comparada e Intercâmbios (Afdece), em seguida os textos apresentados foram publicados. Ver FRANCIS, V; BARBOSA, V. Figures de l'enfant noir et approches de l'altérité en France et au Brésil. L'exemple des albums de jeunesse sur le thème de la musique. In GROUX, D; VOULGRE, E; COMBEMOREL, C; LANGOUËT, G (Org.), Réformer l'école? L'apport de l'éducation comparée - Hommage à Louis Porcher. Paris : L'Harmattan. 2017. p. 568-586.
}

Revista Interinstitucional Artes de Educar. Rio de Janeiro, V. 6, N.2- pág. 713-734 maio-agosto de 2020: "Bebês e crianças: cultura, linguagem e políticas" 


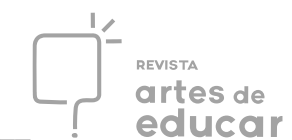

brasileiras passaram a oferecer todo ano uma variedade de livros infantojuvenis representando personagens negros - crianças e adultos - protagonistas, cujas histórias são acompanhadas de diferentes referências geográficas, históricas e culturais do Brasil e da África. A obra literária, uma forma de expressão que apresenta uma interação de textos (que podem ser subjacentes) $e$ imagens (espacialmente preponderantes) em um suporte, caracterizado por uma organização livre da página dupla, uma diversidade de relações materiais e uma sequência fluida e coerente de uma página a outra (VAN DER LINDEN, 2006, p. 87) se harmonizam aqui com trechos ou obras musicais completas que enriquecem e complexificam o sistema de significados. O objetivo desta contribuição é examinar, a partir de obras emblemáticas, as abordagens da alteridade. Quais são as representações das crianças negras nessas obras literárias e como a música intervém nas abordagens da alteridade?

\section{ARTES, INTERCULTURALIDADE E ALTERIDADE}

As artes revelam significativamente as relações entre as culturas (LUCRECE, 2004). No que se refere à música, ocorreu uma incontestável fusão devido à circulação e movimento dos povos em um contexto violento das colonizações espanhola, portuguesa, francesa e inglesa que deram origem ao deslocamento forçado das populações africanas e em seguida, após a abolição da escravidão, ao estabelecimento de movimentos migratórios de mão de obra de homens e mulheres da Índia e da China. Esse movimento contribuiu para um vasto caldeirão que revela, de acordo com Todorov (1989), que a interculturalidade é constitutiva do cultural. As artes são portadoras da interculturalidade. Tanto a música quanto a literatura tornam acessíveis as referências culturais e o contato entre os povos, mesmo que tenham surgido em contextos particularmente brutais, como o tráfico de escravos e o comércio triangular ou ainda a colonização. A violência do choque colonial não conseguiu limitar a necessidade de preservar e transmitir, nem "os processos de troca, empréstimo, integração" tão pouco as referências das heranças culturais (LUCRECE, 2004). Nesses contextos de mobilidade de populações, as artes são poderosas reveladoras de miscigenação, convergência e disseminação que revelam os legados e a força da criação associados à necessidade de resistir e lutar contra as dominações. Enquanto a música constitui um revelador da vitalidade das trocas entre culturas e do poder da criação artística, a literatura multiplica as possibilidades de acesso às referências. Ao associar narrativas visuais, escritas e sonoras, os livros infantis, que têm a música como temática,

Revista Interinstitucional Artes de Educar. Rio de Janeiro, V. 6, N.2- pág. 713-734 maio-agosto de 2020: "Bebês e crianças: cultura, linguagem e políticas"

DOI: 10.12957/riae.2020.48924 
transmitem, assim, múltiplas ancoragens à história das sociedades e indivíduos. Alguns deles visam testemunhar a influência das artes em termos de interculturalidade e conhecimento de si e dos outros. Um dos valores fortemente afirmados pela literatura infantojuvenil diz respeito à alteridade, especialmente centrado na diversidade cultural, uma dimensão que às vezes está intimamente associada à diversidade melânica (DOUGLAS, 2013).

Nessa perspectiva, a alteridade corresponde a qualquer relação socialmente construída, socialmente definida por mecanismos de identificação ou diferenciação de posições, recursos e papéis sociais (PAYET; LAFORGE, 2008). Essa definição mostra que essa abordagem revela uma concepção "complexa e híbrida" (MOLAR, 2008).

\section{ABORDAGENS À DISCRIMINAÇÃO NA FRANÇA E NO BRASIL, ALTERIDADE E FERRAMENTAS EDUCATIVAS}

Seja na França ou no Brasil, a escola é hoje confrontada com uma crescente demanda por pluralismo cultural (DELORY-MOMBERGER; MABILON-BONFILS, 2015, p.6). Essa demanda faz parte de uma educação na e para a diversidade (ABRAMOWICZ; RODRIGUES, 2011). No entanto, a escola é um microuniverso de relações plurais marcadas por desigualdades, exclusões, preconceitos, além de discriminação e racismo (CAVALLEIRO, 2001). A escola, como teatro desses confrontos, assume ao mesmo tempo a função de mediar essas relações sociais, pela compreensão da diferença, a fim de aprofundar a questão da alteridade (HALL, 2007).

No contexto brasileiro, a abordagem da alteridade é recente e faz parte do quadro educacional, principalmente nas políticas públicas de inclusão racial e social. A representação da alteridade aparece nas políticas públicas que orientam o ensino nas escolas no final dos anos 90 . Em 1997, o Ministério da Educação introduziu os "Parâmetros Curriculares Nacionais (PCN's)", nos quais a "pluralidade cultural" constitui-se em um dos temas transversais da educação básica. Assim, a abordagem da diversidade e da alteridade surgiram nos currículos escolares. Posteriormente, foram promulgadas legislações de $2003^{2}$ e 2004 que estabeleceram políticas

\footnotetext{
${ }^{2}$ Em 2003, foi promulgada a Lei ${ }^{\circ} 10.639$, tornando obrigatório o ensino de história e cultura afro-brasileira e africana em todas as escolas, públicas e privadas, em disciplinas como literatura, história e artes visuais que, no ano seguinte, foram reforçadas pelas Diretrizes Curriculares, especificando as modalidades de aplicação da lei em questão. Ressaltamos que a Lei $n^{\circ} 11.645$, de 10 março de 2008 foi promulgada alterando assim a Lei ${ }^{\circ} 9.394$, de 20 de dezembro de 1996, modificada pela Lei $\mathrm{n}^{\circ}$ 10.639, de 9 de janeiro de 2003, que estabelece as diretrizes e
}

Revista Interinstitucional Artes de Educar. Rio de Janeiro, V. 6, N.2-pág. 713-734 maio-agosto de 2020: "Bebês e crianças: cultura, linguagem e políticas"

DOI: 10.12957/riae.2020.48924 


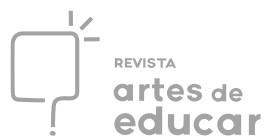

públicas para a "educação étnico-racial", enfatizando a questão da diversidade e do reconhecimento das diferenças no sistema educacional (SANTOS, 2007). Além das Diretrizes Curriculares Nacionais que orientam o ensino de História e Cultura Afro-brasileira e Africana (BRASIL, 2004). A noção de alteridade prevista por essas políticas visa levar em consideração a diversidade étnico-cultural que constitui a sociedade brasileira (BRASIL 1997; 2003; 2004, 2013).

Essas medidas defendem novas formas de educação compensatória e mais igualitária (SILVA, 2007), a fim de promover a visibilidade e a inclusão de grupos sociais historicamente negligenciados na sociedade brasileira, mas também ausentes nos materiais pedagógicos e livros infantis e juvenis utilizados nas escolas.

Essa abordagem pela educação das relações étnico-raciais e da diversidade presente nas políticas educacionais envolve produzir imagens e significados próprios, para lutar contra os preconceitos e estereótipos responsáveis pelo processo de inferiorização elou subordinação desses grupos sociais (ABRAMOWICZ; RODRIGUES, 2011, p. 245). No entanto, a alteridade não é apenas um chamado vago e benevolente à tolerância e ao respeito pela diversidade e pela diferença (DA SILVA, 2000, p.73). É também uma nova perspectiva de compreensão do local e do global, do aqui e dos outros lugares, de si e do outro, em suas dimensões cultural, étnicoracial, linguística, religiosa, social e histórica. De fato, considerar a alteridade significa considerar as múltiplas dimensões que constituem a diversidade étnico-cultural característica da formação da população brasileira.

O reconhecimento individual e coletivo dessa diversidade étnico-cultural no Brasil passa pela educação e, mais particularmente, pela escola, que oferece o suporte, principalmente por meio de livros, com vistas a estabelecer trocas, debates, modelos e práticas emancipatórias que questionem as novas modalidades de convivência e inclusão social (BARBOSA; SIROTA, 2016).

No que diz respeito ao contexto francês, a questão do reconhecimento da discriminação étnico-racial nas escolas é também recente, apesar de estudos mais antigos já mostrarem o peso dos processos segregativos nas escolas (DEBARBIEUX, 1996; PAYET, 1998; FELOUZIS, LIOT; PERROTON, 2005). Vários estudos destacaram a discriminação e insistiram na legitimidade de levar em conta a questão étnico-racial, inclusive em contextos educacionais e de

bases da educação nacional, para incluir no currículo oficial da rede de ensino a obrigatoriedade da temática "História e Cultura Afro-Brasileira e Indígena".

Revista Interinstitucional Artes de Educar. Rio de Janeiro, V. 6, N.2-pág. 713-734 maio-agosto de 2020: "Bebês e crianças: cultura, linguagem e políticas" 
formação (LORCERIE, 2003a, BRINBAUM, MOGUEROU; PROMON, 2010; DHUME, 2011). As discriminações causam estresse, ressentimento e agressão, enfraquecem a autoestima, influenciam fortemente o clima escolar e pesam sobre as tensões étnico-raciais (LORCERIE, 2003b).

Os estudos para medir o peso das discriminações foram desenvolvidos na França para conduzir, nas escolas, uma reflexão sobre a prevenção e o tratamento da discriminação étnicoracial, tendo em vista uma convivência que integre os desafios da diversidade. A influência das políticas públicas europeias sem dúvida explica o esboço desse movimento em um contexto republicano desfavorável ao reconhecimento das singularidades, tanto em suas dimensões regionais, linguística ou étnico-cultural quanto melânica. De fato, as pesquisas se desenvolvem a partir de 2000, quando o Conselho da União Europeia, em sua Declaração sobre Diversidade Cultural, considera que o respeito à diversidade "é uma condição essencial para a vida das sociedades humanas" e convida os membros do Conselho a apoiá-la e promovê-la. Um Livro Branco publicado em 2008 Viver juntos com a mesma dignidade, deu ao diálogo intercultural um lugar central e o considerou como a única possibilidade para reduzir as tensões identitárias e raciais (CONSELHO DA UNIÃO EUROPÉIA, 2008). Essa abordagem leva ao reconhecimento da questão negra (NDIAYE, 2006; BLANCHARD, 2011), nas áreas da educação e formação, inclusive focando nas representações das singularidades melânicas nas ferramentas escolares, incluindo a literatura infantojuvenil (FRANCIS, 2011).

Desde 2014, a Lei de Refundação da Escola mobiliza particularmente duas vertentes: o ensino da moral laica, da instrução e da educação cívica para construir uma melhor convivência na sociedade, para capacitar os alunos a adquirir e entender a necessidade de respeito às pessoas, suas origens e diferenças, mas também à igualdade entre mulheres e homens. E a segunda vertente é a educação artística e cultural considerada uma poderosa alavanca de emancipação e integração social.

As políticas educacionais visam reconhecer a diversidade e prevenir a discriminação em diferentes níveis. Ações e projetos para a prevenção da violência e discriminação com base na origem ou filiação religiosa são valorizados todos os anos durante a semana de educação e ações contra o racismo e o antissemitismo. O plano de ação nacional lançado em 2015 estabeleceu uma parceria com a delegação interministerial da Luta Contra o Racismo e o Antissemitismo (LICRA), a fim de sensibilizar os atores da comunidade educativa e os estudantes para a prevenção do racismo, antissemitismo e todas as formas de discriminação. $\mathrm{O}$ plano também 


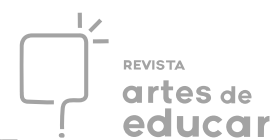

apoia projetos educacionais de combate ao preconceito, estereótipos, racismo, antissemitismo, xenofobia, a fim de cultivar a tolerância e o enriquecimento mútuo e promover uma sociedade de solidariedade e convivência (MENESR, 2017a, s.p.). O objetivo deste plano é "agir a longo prazo para mudar as mentalidades e instaurar uma sociedade mais fraterna" ${ }^{3}$. A Lei de 8 de julho de 2013 sobre orientação e programação para a reforma da escola e da República estabelece o objetivo de melhorar o clima escolar e atuar na prevenção da violência para reconstruir uma escola serena e cidadã revitalizando a vida escolar, prevenindo e lidando com problemas de violência e insegurança. $\mathrm{O}$ combate à violência e à discriminação leva a apoiar ações destinadas a prevenir uma ampla gama de ataques à integridade física e à dignidade do indivíduo, incluindo assédio, violência homofóbica, sexual, sexista, racista e antissemita.

$\mathrm{Na}$ França, os programas do ensino fundamental implementados em setembro de 2016 especificam os objetivos, principalmente na parte três, que diz respeito à formação do indivíduo e do cidadão (MENESR, 2015). Eles estipulam que o acesso a valores morais, cívicos e sociais se baseiam em situações concretas, de confrontos com a diversidade de textos e obras. A educação moral e cívica, em particular, visa confrontar a criança com dilemas morais simples, exemplos de preconceitos, reflexões sobre justiça e injustiça, a fim de sensibilizá-la para uma cultura de julgamento moral.

Para o ciclo três (na França) ${ }^{4}$, que corresponde os dois últimos anos do ensino fundamental I (no Brasil), ainda no que se refere a formação do indivíduo e do cidadão, os programas especificam que o conjunto do ensino escolar deve contribuir para desenvolver a confiança em si mesmo e o respeito pelos outros (Ibid., s.p.). A educação física e o esporte devem permitir aprender sobre o respeito, sobre abolir a discriminação e a aplicação dos princípios da igualdade de gênero (Ibid., s.p.). As artes devem contribuir para o

\footnotetext{
${ }^{3}$ Estes documentos oficiais não são paginados. Eles podem ser consultados na referência citada na bibliografia.

${ }^{4} \mathrm{O}$ sistema de ensino francês é estruturado da seguinte forma : Creche (0 a 2 anos), a Escola Primária que inclui a Escola Maternal (3 a 5 anos) e a Escola Elementar (6 à 11 anos) formando assim 3 ciclos de aprendizagem. Ou seja, o $1^{\circ}$ ciclo corresponde a Escola Maternal - composta por três níveis : pequena, média e grande seção (no Brasil corresponde a Educação Infantil); o $2^{\circ}$ ciclo também é composto por três níveis : CP, CE1, CE2 e o $3^{\circ}$ ciclo formado por dois níveis : CM1 et CM2 (no Brasil o Ensino Fundamental I). Em seguida o Colégio - composto por quatro níveis : o sexto, o quinto, o quarto e o terceiro ano (no Brasil o Ensino Fundamental II), depois o Lycée (no Brasil o Ensino Médio) composto por três anos de escolaridade : o segundo, o primeiro e o terminal. Na França o Lycée tem três seguimentos : Lycée Geral, Lycée tecnológico ou Lycée Profissional, os alunos escolherão no final do último ano do colégio francês qual seguimento seguirão, equivalente no Brasil ao último ano do Ensino Fundamental II.
} 
desenvolvimento da sensibilidade, tanto através da prática artística, conhecendo obras de arte, quanto pela expressão de emoções e gostos da criança. O ensino do língua francesa deve favorecer "a recepção sensível de obras literárias".

Desde 2002, na França, o Ministério da Educação oferece coleções literárias para construir uma herança comum compartilhada por crianças em idade escolar. A primeira delas, composta por 180 títulos direcionados às classes do ensino fundamental, foi amplificada ao longo dos anos. Em 2013, quatro listas foram propostas para a educação infantil e para os ciclos 1 e 2 do ensino fundamental, respectivamente. Essas seleções, que dividem as obras em várias categorias - contos, romances, poemas, teatro etc. - visam apresentar às crianças a diversidade de estilos literários. Assim, o texto introdutório que acompanha a lista da educação infantil menciona que a seleção tem como objetivo principal "permitir uma primeira entrada na cultura literária, oral e escrita" (MENESR, 2017b, s.p.) para introduzir as crianças à manipulação de livros e à prática da leitura, para familiarizá-las com "usos elaborados da língua e da linguagem". No ensino fundamental, trata-se, de acordo com o texto de uma apresentação que introduz a lista de livros, formar um aluno leitor, oferecer mídias variadas e ricas, tanto linguisticamente quanto em termos de conteúdo (MENESR, 2017b, s.p.). Se o foco estiver bem posicionado na iniciação à leitura da literatura, os livros deverão responder às questões dos jovens leitores, "para propor uma abertura sobre o mundo de ontem e de hoje" e "para incentivar o desenvolvimento da imaginação e da cultura."

\section{APRESENTAÇÃO DE CONTEXTOS, METODOLOGIA}

Este texto é baseado em uma análise secundária dos resultados de estudos realizados no contexto francês, que examinaram as imagens e representações de crianças negras em livros ilustrados (FRANCIS, 2011; 2015), especialmente sobre o tema da música (FRANCIS, 2016). O corpus também é composto por discursos produzidos por instituições de referência, em particular as editoras, acessíveis gratuitamente na Web. Uma breve visão geral será proposta antes de se concentrar em dois trabalhos nas listas propostas pelo Ministério da Educação Nacional francês, nos quais o personagem central, uma criança negra, está no centro de uma história sobre música. Esses dois livros podem ser considerados obras emblemáticas por causa da promoção feita pela instituição escolar e pelo lugar que as editoras e livrarias reservam para eles.

Revista Interinstitucional Artes de Educar. Rio de Janeiro, V. 6, N.2- pág. 713-734 maio-agosto de 2020: "Bebês e crianças: cultura, linguagem e políticas"

DOI: 10.12957/riae.2020.48924 
Em relação ao Brasil, o estudo se baseia em uma pesquisa de campo realizada em sete escolas públicas brasileiras da cidade de Salvador, na Bahia ${ }^{5}$, por meio de duas metodologias complementares: observações em sala de aula e análise de conteúdo de 12 livros ${ }^{6}$ para crianças, que tenham a música como tema e a criança negra como personagem principal, publicados a partir de 2000 e enviados pelo Ministério da Educação ${ }^{7}$ a essas escolas. Vamos nos concentrar especialmente em um deles, que é representativo das tendências que emergem dos resultados gerais.

Na França e no Brasil, as obras são frequentemente objetos híbridos. O livro é então um documento em papel e som, graças a uma seleção em uma mídia eletrônica, um site usando um modo de difusão contínua como o Deezer, ou um CD. Nesses suportes, a parte sonora geralmente inclui uma história composta por uma partitura dupla com a presença de voz e música.

A outra dimensão híbrida dos livros está ligada à associação conjunta de texto e imagem (NIÈRES-CHEVREL, 2009), que constitui uma narrativa dupla (POSLANEIC, 2003) e a mistura entre ficção e documentário. Nuances cronológicas e mapas geográficos estão frequentemente presentes para situar os lugares da narrativa, para indicar o surgimento e a disseminação de gêneros musicais e, de maneira mais geral, para expor o itinerário do músico. A dimensão biográfica está, portanto, particularmente presente com fotografias que atestam a vida dos personagens, às vezes desde o período da infância. Os esboços biográficos também incluem subdivisões: pôsteres, extratos da imprensa ou correspondência. Esses elementos ecográficos e

\footnotetext{
${ }^{5}$ Salvador é marcada por uma grande população negra, um percentual que chega a $80 \%$ e, portanto, um dos municípios mais engajados com a implementação dessas políticas públicas de 2003 e 2004 e 2009 para educação das relações étnico-raciais. É importante notar que a implementação dessas políticas está intimamente ligada ao compromisso de cada município brasileiro com a população negra em geral, mas também com a presença e participação de movimentos negros em particular em algumas cidades do país. Sendo a cidade de Salvador o campo de nossa pesquisa, sobre ela afirma-se que possui um total de 437 escolas municipais, que incluem creches, educação infantil e escolas de ensino fundamental. Veja: http://educacao.salvador.ba.gov.br/educacao-em-numeros/, acessado em 7 de janeiro de 2020.

${ }^{6}$ Estas obras são as seguintes: Asare, Meshack. O chamado de Sosu. São Paulo, SM, 1997 ; Barbosa, Rogério. Rio acima, mar abaixo. São Paulo, Melhoramentos, 2005 ; Costa, Madu. Koumba e o tambor diambê. Belo Horizonte, Mazza, 2012 ; Da Vila, Matinho. A rainha da Bateria. São Paulo, Lazuli, 2009 ; Ferreira, Elita. O berimbau encantado. Recife, Bagaço, 2008; Furtado, Maria C. Pretinho, meu boneco querido. São Paulo, Do Brasil, 2008 ; Hetzel, Beatriz B. Berimbau mandou te chamar. Rio de Janeiro, Manati, 2008 ; Lotito, Iza. O herói de Damião: em a descoberta da capoeira. São Paulo, Girafinha, 2006 ; Macedo, Aroldo \& Faustino, Oswaldo. Luana, a menina que viu o Brasil neném. São Paulo, FTD, 2000 ; Pereira, Edimilson. Os Reizinhos de Congo. São Paulo, Paulinas, 2007 ; Prandi, Reginaldo. Ifá, o adivinho. São Paulo, Companhia das Letrinhas, 2002 ; Santos, Joel R. Dos. Dudu Calunga. São Paulo, Ática, 1986.

${ }^{7}$ Cabe destacar que esses livros são enviados pelo "Programa Nacional de Bibliotecas Escolares (PNBE)" do Ministério da Educação, como parte das políticas públicas em prol da leitura. Criado em 1997, sob a direção do Fundo Nacional para o Desenvolvimento da Educação (FNDE), este programa promove a distribuição de coleções e livros de literatura infantojuvenil para escolas públicas brasileiras.
}

Revista Interinstitucional Artes de Educar. Rio de Janeiro, V. 6, N.2- pág. 713-734 maio-agosto de 2020: "Bebês e crianças: cultura, linguagem e politicas"

DOI: 10.12957/riae.2020.48924 
ego-geográficos (FRANCIS, 2014) nomeiam a cor dos personagens, destacando a questão melânica na imagem e, algumas vezes, incorporando-a explicitamente no texto.

\section{SUBDIVISÕES E ATRIBUIÇÕES DENTRO DE COLEÇÕES}

Na produção francesa mais veiculada na França, as obras que têm a música por tema estão particularmente relacionadas à questão negra. Os heróis das obras que apresentam as percussões, o gospel, o blues, o jazz, o samba... são quase exclusivamente personagens de cor negra. Se meninos e homens são super-representados, o lugar dos estereótipos também se refere ao gênero da música, já que os personagens negros são quase invisíveis quando as obras ou títulos dizem respeito a outros gêneros musicais, como a música clássica. As representações das práticas musicais permanecem, portanto, "enquadradas" (RAIBAUD, 2010). Além disso, quando as histórias se situam nos espaços das Antilhas, do Caribe ou da África, os jovens heróis são quase invariavelmente associados às imagens de terras virgens e da vida tribal. $\mathrm{O}$ estudo de coleções sobre a temática música é, neste aspecto, edificante. Mostra que os personagens das crianças brancas podem sistematicamente ser encenados em ambientes favoráveis, enquanto as crianças negras evoluem nesses espaços míticos de origem ${ }^{8}$ mais próximos da natureza e do ambiente natural (FRANCIS, 2016). Outro tema recorrente é o da pobreza, que está fortemente presente em livros que tratam de música africana, brasileira e cubana. Várias histórias ilustram esse assunto, como a história de Jorginho, que sai da floresta para se tornar um "engraxate" em uma das favelas do $\operatorname{Rio}^{9}$ ou ainda a reportagem fotográfica sobre percussão em Cuba ${ }^{10}$.

Apenas raras obras oferecem imagens de conexões e contatos entre culturas, permitindo diálogos interculturais e links entre gêneros artísticos, música, dança, artes circenses. ${ }^{11}$ Os textos de apresentação das editoras incidem sobre a abertura ao mundo e ao intercâmbio entre culturas. Mas essa proposta pode ser desacreditada pelas escolhas estéticas que dominam coleções

\footnotetext{
${ }^{8}$ Veja, por exemplo, a coleção publicada pela Actes Sud Junior, Contos do Museu da Música: Angèle, l'ange du clavecin de Marie Bertherat, ilustrado por Claire De Gastold; Wambi le chasseur d'antilopes, de Anne Montange, ilustrada por Frédéric Rébéna, música de Jean Loulendo e Sally Nyolo, 2001; Kim le gardien de la terre de Anne Montange, ilustrada por Ohrun Emre, música de Jean Loulendo e Sally Nyolo, 2007.

${ }^{9}$ La musique brésilienne : Les petits cireurs de chaussures, de Béatrice Fontanel ilustrada por Charlotte Gastaut, Gallimard Jeunesse, Coleção Descoberta de músicas do mundo, 2011.

${ }^{10}$ Antón et la musique cubaine, de Emmanuel Viau, ilustrada por Olivier Tallec, fotos de Stéphane Lagoutte, Gallimard Jeunesse, coleção Musiques d'Ailleurs, 1998.

${ }^{11}$ La danse moderne, de Dominique Boivin, Christine Erbé e Philippe Priasso, Gallimard Jeunesse, coleção Carnets de danse, 1998.
}

Revista Interinstitucional Artes de Educar. Rio de Janeiro, V. 6, N.2-pág. 713-734 maio-agosto de 2020: "Bebês e crianças: cultura, linguagem e politicas" 


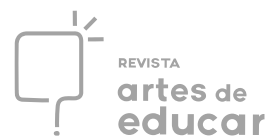

fortemente marcadas por estereótipos e pelas atribuições de jogos de determinado gênero musical, de tal grupo melânico, branco ou preto, ambiente favorável ou miserável, imagem arquetípica. As representações étnico-raciais, bem como as escolhas de confinar as histórias a áreas espaciais definidas, merecem ser questionadas, a fim de sair da lógica de modelos simplificadores. Frequentemente escritas na metáfora das raízes, essas histórias tendem a racializar a cultura, tornando-a uma substância cujo desenvolvimento requer um terreno comunitário (um povo, uma raça, um grupo étnico), ou seja, uma base biológica que coloca como um dado a diferença radical dos grupos humanos (DORIN, 2006, p.129). Isso contradiz a realidade de uma dinâmica alteritária associada aos contatos de culturas e trocas, operada por movimentos de miscigenação, hibridismo e criação, nos quais a cultura integra uma economia de trocas e de empréstimos (idem, p. 144).

\section{NA FRANÇA, IMAGENS DE CRIANÇAS NEGRAS INSCRITAS NOS TERRITÓRIOS DA ÁFRICA MITIFICADA E DA AMÉRICA SEGREGACIONISTA}

Os livros com personagens de crianças negras não estão muito presentes nas listas propostas pelo Ministério da Educação Nacional. A do ciclo dois da escola primária inclui 270 livros. Oito ${ }^{12}$ apresentam um personagem negro, menino ou menina, incluindo Jujube. Se não houver música, o livro é uma exceção, porque o autor tenta impedir estereótipos clássicos presentes quando as histórias são encenadas por crianças negras. O livro desconstrói os imaginários associados à África com base na referência à natureza exuberante, aos grandes animais dos espaços preservados e à vida tribal (FRANCIS, 2015).

$\mathrm{Na}$ lista proposta para a educação infantil, que possui 250 livros, dois títulos ${ }^{13}$ referem-se a um personagem negro, ambos do sexo masculino. O livro La batterie de Theophile, faz parte do corpus. Publicado em 1989, foi reeditado em 2003 acompanhado por um CD. Apresenta um

\footnotetext{
12 Bannerman, Helen et Marcellino, Fred. Le grand courage de Petit Babaji. Paris, Bayard Jeunesse, 1998 ; Bebey, Kidi et Epanya, Christian Kingue. Pourquoi je ne suis pas sur la photo ? Paris, EDICEF, 1999 ; Epanya, Christian Kingue. Le taxi-brousse de papa Diop. Paris, Syros, 2005 ; Lucca et Arno. Tu t'occuperas de Petit-Frère. Paris, Casterman, 2002 ; Laroche, Agnès et Boyer, Vincent. Cours, Ayana! Paris, Rageot, 2006 ; Pinguilly, Yves et Koenig, Florence. La couleur des yeux. Paris, Autrement Jeunesse, 2001 ; Weulersse, Odile, Bryant, Sara Cone et Chaplet, Kersti. Épaminondas. Paris, Flammarion - Père Castor, 1999; Wilsdorf, Anne. Jujube. Paris, Kaléidoscope, 1998.

${ }^{13}$ Claverie, Jean. La batterie de Théophile. Paris, Gallimard Jeunesse, 1989 ; Cooke, Trish et Oxenbury, Helen. Très, très fort ! Paris, Flammarion - Père Castor, 1995.
}

Revista Interinstitucional Artes de Educar. Rio de Janeiro, V. 6, N.2-pág. 713-734 maio-agosto de 2020: "Bebês e crianças: cultura, linguagem e politicas"

DOI: 10.12957/riae.2020.48924 
garotinho negro tocando percussão com uma tigela e um graveto, e os animais que encontra durante sua jornada na selva e finalmente, tocando com um tambor.

$\mathrm{Na}$ lista das classes do ciclo três, dos 300 livros, três títulos ${ }^{14}$ retratam uma personagem negra: Maman-dlo conta a história de Cécette separada da mãe que foi trabalhar na França; o relato autobiográfico Leon, refere-se à vida do autor nascido em 1936, confrontado ao racismo e à pobreza, depois envolvido na luta pelo acesso aos direitos civis seguindo Martin Luther King. O terceiro título que faz parte do corpus, corresponde a um gênero pouco representado, o romance gráfico. Little Lou, é de autoria de Jean Claverie, autor de La batterie de Théophile. Foi publicado pela primeira vez em 1990 e retrata a história de Lou na América segregacionista. Como muitos livros que têm a música como tema, a história está associada à questão negra, nas quais os episódios biográficos da infância negra testemunham esses contextos de vida em que coexistem pobreza e violência (FRANCIS, 2015; 2016).

Desde a primeira página, a imagem incorpora um desses atributos que tipificam a infância negra nos livros ilustrados: pés descalços. O tio do jovem herói, ainda adolescente, vai de fazenda em fazenda para cantar o blues. Esta história, iniciada na década de 1920, é pontuada por muitos episódios de sofrimento, incluindo insegurança devido a agressões racistas. No entanto, é também retratado o desenvolvimento musical do jovem, como o prazer de cantar durante os cultos de domingo, aulas de piano e momentos de compartilhamento, nos quais se opera a transmissão de uma herança musical ancestral tocada para não cair no esquecimento.

Ao retratar Slim, o velho pianista que toca todas as músicas do tio Sonny e que se vai em uma noite de inverno, a história destaca os papéis dessas figuras excepcionais que apresentam a arte e a cultura para os jovens afro-americanos de bairros pobres. As transmissões transgeracionais permitem o acesso à arte através do compartilhamento, conforme especificado por Memphis Slim no prefácio: "os mais velhos transmitem através de laços de amizade, as raízes do blues (...) uma arte de viver onde se mistura dor, riso, amor e música".

Enquanto a instituição escolar e as bibliotecas participam da consagração desses dois livros selecionados por critérios didáticos, estéticos e literários, são valorizadas duas imagens da criança negra: aquela inscrita em uma alteridade que evoca a história da criança negra da América segregacionista e aquela associada aos territórios da África mitificada (FAUVELLEAYMARD, 2013). Por um lado, a imagem da criança negra aparece relacionada aos contextos

\footnotetext{
${ }^{14}$ Claverie, Jean. Little Lou. Paris, Gallimard Jeunesse, 1994 ; Godard, Axel. Maman-dlo. Paris, Albin Michel Jeunesse, 1998 ; Tillage, Léon Walter et Roth, Susan. Léon. Paris, L'École des loisirs, 1999.
}

Revista Interinstitucional Artes de Educar. Rio de Janeiro, V. 6, N.2-pág. 713-734 maio-agosto de 2020: "Bebês e crianças: cultura, linguagem e politicas" 


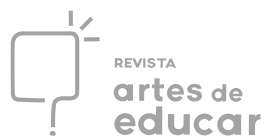

sociais da história da música negra e suas figuras emblemáticas, ancorada nas imagens de um espaço extraterritorial e segregacionista. Por outro, essa imagem é construída sobre um conto irônico, em que a criança negra, colocada em uma situação cômica, tenta tocar percussão martelando uma bacia ou domando uma jiboia, um rinoceronte e um crocodilo. A abordagem da alteridade é traçada aqui sem possíveis ligações entre o aqui e o lá fora, o si mesmo e os outros, associada a uma exterioridade referida à experiência radical da segregação ou ao imaginário da África ancestral.

\section{NO BRASIL, O TEMA DA IDENTIDADE RACIAL}

Para a produção brasileira, seja uma herança musical de origem afro-brasileira ou africana, muitas obras infantis que têm a música como tema, desempenham principalmente um papel de vetor entre passado e presente para abordar a temática da identidade racial. Cabe ressaltar que esses títulos se tornam um suporte cultural e educacional, ao qual vários conteúdos temáticos são associados e lidos como: a cartografia da diáspora negra no Brasil; os quilombos ${ }^{15}$ como espaços de residência e patrimônio cultural (ANDRADE, 1997); as datas do calendário escolar, o 13 de maio para a comemoração da abolição da escravidão e o 20 de novembro para o Dia Nacional da Consciência Negra; as personalidades negras; as práticas culturais como capoeira, samba e carnaval; a Religiosidade afro-brasileira; a estética negra, incluindo cor da pele, cabelos e penteados, agora inseridos num processo de revalorização que combina com a aparência para reconhecer a filiação étnico-racial (GUIMARÃES, 2011). Essas diferentes referências geográficas, históricas, culturais, estéticas e até religiosas, mobilizadas por esses livros, criam um elo entre a origem e pertencimento etnocultural (MUNANGA, 2015), levantando a questão da diversidade e do reconhecimento das diferenças nas políticas educacionais (ABRAMOWICZ; RODRIGUES, 2011).

O tema da música, articulado a essas múltiplas referências, como o cenário, conduz à utilização do texto e do design gráfico para abordar a "dimensão intercultural" (ABADALLAHPRETCEILLE, 1996). ${ }^{16}$ Por meio de movimentos constantes associando o aqui e outros lugares, conectando o si mesmo e os outros, que se constrói a dimensão da alteridade dentro e através

\footnotetext{
${ }^{15}$ Os quilombos eram microssociedades formadas por "ex-escravos" e estavam na origem de rebeliões abolicionistas. Eles representavam uma "experiência negra" (HALL, 2007) que permitiu preservar as crenças, a cultura e a "memória" da população negra brasileira.

${ }^{16}$ A esse respeito, Abadallah-Pretceille (1996, pp. 158-159) enfatiza que a pedagogia intercultural "não se destina a ensinar culturas, sejam nossas ou outras, mas redimensionar a todo aprendizado sua dimensão cultural".
}

Revista Interinstitucional Artes de Educar. Rio de Janeiro, V. 6, N.2- pág. 713-734 maio-agosto de 2020: "Bebês e crianças: cultura, linguagem e politicas"

DOI: 10.12957/riae.2020.48924 
desses objetos culturais infantis, os livros ilustrados. A literatura infantojuvenil aparece na agenda das políticas públicas brasileiras como uma ferramenta importante para provocar reflexões sobre questões étnico-raciais (SILVA, 2014, p. 14). De fato, esses livros revelam a intenção de participar da construção da identidade racial dos jovens leitores, uma identidade considerada aqui - como raça e gênero - como construção social e cultural historicamente elaborada por meio de relações sociais e de poder, feita de semelhanças e diferenças entre o si e o outro, para uma produção (HALL, 2007, p. 311) nunca concluída, e que é construída, reconstruída e desconstruída em um processo de mutação permanente.

No contexto da produção brasileira, a abordagem da alteridade é privilegiada por abordar a questão da diversidade étnico-racial, particularmente relacionada à cor da pele, por meio de um questionamento identitário ${ }^{17}$ do personagem da criança negra. Um retorno às suas origens africanas é o caminho essencial utilizado por essas obras para estimular o reconhecimento e a valorização de um pertencimento racial desses personagens, movimento visando por extensão os jovens leitores. Para cantar suas origens são mobilizadas várias referências culturais: instrumentos musicais - como tambor e berimbau; as canções de ontem e hoje, algumas gravadas em CD; heróis e personalidades da história.

Vamos agora analisar um livro emblemático Pretinho, meu boneco querido (2008), escrito por Maria Cristina Furtado, que ilustra essa descrição com precisão.

Nininha é uma menininha negra. Ela tem uma coleção de bonecas e bonecos que têm vida. Pretinho ${ }^{18}$ é seu boneco favorito, mas desperta o ciúme de outros bonecos. Assim que Nininha está fora do quarto, as bonecas e os bonecos aproveitam para maltratar Pretinho, que então se refugia no armário para chorar. Por exemplo, ele escuta: Saia, Pretinho! Você vai deixar sua tinta preta no carrinho e quando eu for brincar, vou me sujar. Aqui, apenas bonecas brancas podem entrar. E os outros bonecos morrem de rir. (...) Não tenho ciúmes de um boneco preto e feio (FURTADO, 2008, p. 4-5). Esse livro conta a história desse boneco vítima de racismo. No entanto, parece que o recurso a um personagem antropomórfico, e não uma criança,

\footnotetext{
17 Acentuamos que Thiery e Francis (2013 e 2015) observaram esse mesmo "questionamento identitário" no estudo das representações da criança negra nos livros ilustrados do contexto francês.

${ }^{18}$ Lembramos que o termo "petit noir" na nossa versão francesa é uma tradução aproximada do português "pretinho" - um adjetivo muito popular no contexto brasileiro para identificar uma pessoa por sua cor e pode ter duas conotações diferentes, dependendo do contexto. Neste título "Pretinho", é um adjetivo que aqui tem uma conotação afetiva. Por outro lado, em outros dois livros do nosso corpus, a tradução de petit noir - desta vez "negrinho" em português - é pejorativa, porque, em francês, corresponderia a "petit nègre". De fato, a mudança de terminologia para designar a cor negra nos livros reflete um desejo de valorizar essa cor, que faz eco às reivindicações do Movimento Negro por uma mudança nos termos usados na vida cotidiana.
}

Revista Interinstitucional Artes de Educar. Rio de Janeiro, V. 6, N.2- pág. 713-734 maio-agosto de 2020: "Bebês e crianças: cultura, linguagem e politicas" 


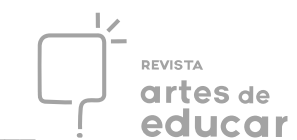

permite o uso de um registro mais duro e violento. Como outros personagens de certas obras que compõem o corpus da seleção brasileira, o boneco expressa o desejo de não ser mais negro: Quero ser branco. Não quero mais ser negro (Ibid., 13). E assim os outros bonecos tomam a decisão de mudá-lo de cor, preparando um banho de espuma para torná-lo branco.

Nininha, a menina, intervém e restaura a confiança em seu boneco vítima de racismo. Ela o move em direção ao amor à negritude", afirma seu orgulho de ser negra, orgulho que herdou do pai que a ensinou que [...] os afrodescendentes são muito importantes porque a cultura africana se encontra em todo brasileiro (Ibid., 14). Ela então diz a Pretinho: Tenho orgulho de ser negra. Você também deve se orgulhar (Ibid., 15). Ela explica aos seus brinquedos que o pertencimento étnico-racial é importante e que, longe de apagá-lo, deve-se valorizá-lo, exemplo de muitas mensagens endereçadas indiretamente ao jovem leitor negro. E assim, ela chama seus bonecos para dançar e cantar ao ritmo da batucada que aprendeu na escola quando sua professora comemorou o Dia Nacional da Consciência Negra. O livro acompanhado por um CD é composto pelas músicas: Branco, preto, amarelo, todas as cores são iguais. Vermelho, azul e roxo, nenhuma cor é melhor que a outra! (Ibid., 14).

\section{ENTRE O BRASIL E A FRANÇA, UMA ABORDAGEM RADICALMENTE DIFERENTE DAS REFERÊNCIAS E ABORDAGENS DA ALTERIDADE}

Em geral, seja na França ou no Brasil, a literatura infantojuvenil proposta por instituições de ensino mostra a diversidade étnico-cultural. Diferentes limites aparecem e examiná-los supõe levar em conta a questão da interseccionalidade situada aqui em torno das relações sociais de raça e gênero. A figura da criança negra está associada, de um lado, a obras patrimoniais que se referem a contextos sócio históricos extraterritoriais ou desenham o espaço imaginário da África exótica. Por outro lado, a figura da criança negra está no centro das histórias que ligam o outro lugar e o aqui, e questionam as realidades do passado e do presente.

No Brasil, as obras literárias selecionadas se concentram no universo da infância. A história é abordada como um vetor potencial e dinâmico de apropriação da história racial nacional e da identidade cultural. $\mathrm{O}$ retorno às origens africanas é abordado através do tema da cor da pele. Isso reflete a evolução do sistema de classificação racial no Brasil descrito por Mumanga (2004). Enquanto anteriormente a classificação se baseava principalmente na 
referência do indivíduo a "grupos de cores" (GUIMARÃES, 1999) e não a grupos raciais, uma mudança está gradualmente ocorrendo à medida que o ideal de branqueamento perde sua força. Essa evolução, na qual a aparência agora é valorizada, refere-se ao pertencimento (GUIMARÃES, 2011), pois está associada à relação intergeracional - de adultos a crianças, mas também entre grupos de pares.

Enquanto no Brasil os livros são abordados como vetores de identidades culturais, na França, a seleção ministerial faz parte da construção de uma cultura literária e de uma didática da linguagem para construir noções literárias, implementar um processo de compreensão, permitir que os alunos desenvolvam sua bagagem linguística e, em particular, seu vocabulário (MENESR, 2017a, s.p.). Paralelamente a essas opções, há uma grande diversidade de obras. Os editores são engajados ${ }^{19}$ em uma política de publicação que leva em consideração os estereótipos e preconceitos disseminados por ferramentas educativas e em renovar as imagens da criança negra transmitidas em livros ilustrados. As coleções ${ }^{20}$ oferecem um espaço plurilíngue, uma linguagem intermediária que rompe com a crença dos etnocentrismos linguísticos (GASQUET, 2007), um ponto forte para o pensamento de línguas e culturas. A construção de alteridades implica a integração de ferramentas escolares que combinam universos sonoros, escritos e gráficos para abordar as dimensões morais, cívicas e socioemocionais de acordo com abordagens abertas, como as desenvolvidas, por exemplo, no contexto de oficinas filosóficas.

\section{CONSIDERAÇÕES FINAIS}

O pertencimento das crianças a uma identidade que seja respeitada a partir de sua inserção na sociedade é complexa e envolve relações sociais de classe, raça e gênero. No caso

\footnotetext{
${ }^{19}$ No contexto brasileiro, classificamos os editores do corpus das obras literárias em dois grupos. O primeiro reúne editoras de grande e médio porte, com grandes tiragens e forte peso no mercado editorial brasileiro. O segundo reúne pequenas editoras e/ou editoras independentes ou ainda editoras militantes. Estes últimos representam uma nova geração de pequenos editores com baixo peso econômico, mas cujo papel não é desprezível para a expressão popular. Elas são engajadas com as demandas dos movimentos sociais brasileiros da década de 1990 visando as demandas dos grupos minoritários. No contexto francês, alguns editores engajados são muito bem representados em territórios franceses fora da França. É o caso, por exemplo, da Editions Classiques d'Expression Française, uma editora cujo objetivo é atender às expectativas de um grande público de língua francesa, da África e do Oceano Índico. Uma de suas coleções, Cameleon Vert, voltada ao público infantil, é desenvolvida em parceria com editoras do espaço africano e Oceania, por exemplo, edições Bakame de Ruanda, Donniya no Mali, Graines de Pensées no Togo, Jeunes Malgaches, Pallas no Brasil ou ainda Ruisseaux na África.

${ }^{20}$ Comptines du monde, Didier Jeunesse : Comptines et berceuses du baobab - L'Afrique noire en 30 comptines collectées par C. Grosléziat, illustrées par E. Nouhen, 2007 ; À l'ombre du flamboyant - 30 comptines créoles : Haiti, Guadeloupe, Martinique et la Réunion, collectées par C. Grosléziat, illustrées par L. Corvaisier, 2013.
}

Revista Interinstitucional Artes de Educar. Rio de Janeiro, V. 6, N.2-pág. 713-734 maio-agosto de 2020: "Bebês e crianças: cultura, linguagem e políticas"

DOI: 10.12957/riae.2020.48924 
deste estudo, o modo como a criança negra é representada na literatura infantojuvenil e na música constrói limites e possibilidades para que ela exista como sujeito na sociedade na qual está inserida, seja no Brasil ou na França. É necessário considerar a alteridade desses sujeitos em suas múltiplas dimensões de modo a superar estereótipos. Se por um lado temos avançado em colocar o tema da criança negra na pauta das políticas públicas para a educação, o estudo mostra que não basta ter o tema como foco dessas políticas. É preciso identificar como esse tema chega em cada contexto. Se as discriminações causam estresse, ressentimento e agressão, enfraquecem a autoestima, influenciam fortemente o clima escolar e pesam sobre as tensões étnico-raciais, esse tema não pode ser negligenciado pelas escolas em seus projetos político-pedagógicos. É preciso olhar para a criança que está aqui e agora, vivendo e constituindo sua identidade através das relações que estabelece cotidianamente, mas que também tem uma origem que a remete a sua ancestralidade, que não pode ser mítica ou segregacionista, mas constituinte de uma história que merece ser contada.

Seja na França ou no Brasil, pesquisas relacionadas a essas políticas educacionais voltadas principalmente para a análise do texto das leis e o conteúdo dos livros infantojuvenis já foram e são desenvolvidas com mais frequência. Assim, o ponto de vista das crianças ainda permanece em grande parte à sombra. Seria muito interessante salientar a importância e necessidade de realizar outros estudos sobre o uso efetivo desses livros nas escolas e de estar interessado também a recepção desses livros pelos alunos.

\section{REFERÊNCIAS}

ABDALLAH-PRETCEILLE, M.; PORCHER, L. Education et communication interculterelle. Presses universitaires de France, 2001.

ANDRADE, T. (Org.). Quilombos em São Paulo: tradições, direitos e lutas. São Paulo: IMESP, 1997.

BARBOSA, V. O que é a literatura infantil afrodescendente?: Em foco a produção literária de 1990 a 2010. In: PEREIRA, R. M. R.; SANTOS, N. de O.; LOPES, A. E. R. de C. (Org.). Infância, juventude e educação: práticas e pesquisa em diálogo. Rio de Janeiro: Nau, p. 113-132, 2015a.

L'image de l'enfant noir... dans les albums de littérature de jeunesse brésilienne. Revue de l'enfance et de l'adolescence, n. 1, p. 203-216, 2015 b.

Revista Interinstitucional Artes de Educar. Rio de Janeiro, V. 6, N.2- pág. 713-734 maio-agosto de 2020: "Bebês e crianças: cultura, linguagem e políticas"

DOI: 10.12957/riae.2020.48924 
BARBOSA, V.; SIROTA, R. Les livres d'enfants, des manuels de civilité contemporains entre formel et informel? Un exemple: l'enfant noir dans la littérature de jeunesse au Brésil. Revista Eletrônica de Educação, v. 10, n. 3, p. 355-367, 2016.

BELOTTI, E. G. Du côté des petites filles. Paris : Editions des femmes, 1974.

BLANCHARD, P. La France noire. Paris : La Découverte, 2011.

BRASIL. Parâmetros curriculares nacionais : introdução aos parâmetros curriculares nacionais. Secretaria de Educação Fundamental. Brasília : MEC/SEF, 1997.

..Lei 10.639 de 9 de Janeiro de 2003. D.O.U. 10 de Janeiro de 2003.

..Diretrizes curriculares nacionais para a educação das relações étnico raciais e para o ensino da História afro-brasileira e africana. Brasília/DF: SECAD/ME, 2005.

.Plano Nacional das Diretrizes Curriculares Nacionais para a Educação das Relações Étnico-Raciais e para o Ensino de História e Cultura Afro-Brasileira e Africana. Brasília: SECAD; SEPPIR, 2013.

BRINBAUM, Y.; MOGUÉROU, L.; PRIMON, J. Parcours et expériences scolaires des jeunes descendants d'immigrés en France. Trajectoires et Origines. Enquête sur la diversité des populations en France, sous la dir. de C. Beauchemin, C. Hamel et P. Simon, Documents de travail de l'INED, n. 168, 2010.

BRUGEILlES, C.; CROMER, I.; CROMER, S. Les représentations du masculin et du féminin dans les albums illustrés. Population, v. 57, n. 2, p. 261-292, 2002.

BRUGEILLES, C. CROMER, S. Analyser les représentations du masculin et du féminin dans les manuels scolaires. Paris : CEPED, collection, Les clefs Pour, 2005.

CAVALLEIRO, E. S. Racismo e antirracismo na educação: repensando nossa escola. Selo Negro, 2001.

CHABROL-GAGNE, N. Filles d'albums: les représentations du féminin dans l'album. L'Atelier du poisson soluble, 2011.

DE L'EUROPE, Conseil. Livre blanc sur le dialogue interculturel" Vivre ensemble dans l'égale dignité". Ed. du Conseil de l'Europe, 2008.

DA SILVA, T. T. ; al. A produção social da identidade e da diferença. Identidade e diferença: a perspectiva dos estudos culturais. Petrópolis: Vozes, p. 73-102, 2000.

DEBARBIEUX, Eric. La violence en milieu scolaire: état des lieux. ESF éditeur, 1996.

Revista Interinstitucional Artes de Educar. Rio de Janeiro, V. 6, N.2- pág. 713-734 maio-agosto de 2020: "Bebês e crianças: cultura, linguagem e politicas" 
DELORY-MOMBERGER, C.; MABILON-BONFILS, B.. L'école et la figure de l'altérité: Peut-on penser et enseigner la diversité dans notre école?. Éducation et socialisation. Les Cahiers du CERFEE, n. 37, 2015.

DHUME, F. De l'(in)égalité de traitement selon "l'origine". Paris : Editions La Documentation française, 2011.

DORIN, S. La métaphore des racines: un obstacle à l'analyse sociologique des dynamiques culturelles. Politix, n. 2, p. 125-147, 2006.

DOUGLAS, V. Littérature pour la jeunesse et diversité culturelle. Editions L'Harmattan, 2013.

FAUVELLE-AYMAR, F. Le rhinocéros d'or: histoires du Moyen Âge africain. 2013.

FELOUZIS, G.; al. L'apartheid scolaire. Enquête sur la ségrégation ethnique dans les collèges. Paris : Seuil, 2005.

FRANCIS, V. Approches et représentations de l'enfant 'noir' et 'de couleur' dans l'éducation de la petite enfance. Symposium au XXIème Conférence Internationale de l'EECERA. Genève, 14-17 sept. 2011.

FRANCIS, V. THIERY, N. Éducation à la diversité et littérature pour la jeunesse: les représentations de l'enfant noir dans les albums illustrés. Communication au congrès de l'AREF/AECSE. Montpellier, p. 27-30, 2013.

FRANCIS, V. Renoncement, résistance, libération. Le récit de soi au prisme du contexte postcolonial. In DE SOUZA, G. B., A ; MILON OLIVEIRA, A-M. (Org.) Écriture de soi, résistance et empowerment (Trad de Renunciamiento, resistencia, liberación. El relato de sí el prisma del contexto poscolonial. In Escrita de si, resistência e empoderamento). Curitiba-Brasil : CRV. Cap.5. p. 83-98. 2014.

FRANCIS, Véronique. Stéréotypes et discriminations ethnoraciales dans et par les albums illustrés pour la jeunesse. Revista Eletrônica de Educação, v. 9, n. 2, p. 67-114, 2015.

FRANCIS, V. La musique dans les ouvrages pour la jeunesse. Variations autour de la question mélanique. In BELHADJIN, A., DALL'ARMELLINA, L. p. 97-113, B., PESCE, S. (Dir.). Je chante donc je suis Tome 1 Ethnicité, musique et politique. Paris : Téraèdre. p. 97-113. 2016.

FRANCIS, V., BOLOGNESI, I. PILERI, A., BIEMMI, I., BARBOSA, V. Educare senza discriminare. Le rappresentazioni delle diversità somatiche e di genere negli albi illustrati . Bologne : Édition Franco Angeli. 2018.

FRANCIS, V., DA SILVA JOVINO, I., BARBOSA, V., ABRAMOWICZ, A. Les représentations des corps noirs dans les albums illustrés pour la jeunesse. In ATZENHOFFER, R. (Org.). Représentations et traductions du corps parlant dans la culture de jeunesse. Cultural Express [em acesso], n. 2. 2019.

Revista Interinstitucional Artes de Educar. Rio de Janeiro, V. 6, N.2- pág. 713-734 maio-agosto de 2020: "Bebês e crianças: cultura, linguagem e políticas" 
GASQUET, A. L'hospitalité des langues ou une invitation à la xenoglossie. In GASQUET, A ; SUAREZ, M. (Org.), Ecrivains multilingues et écritures métisses : L'hospitalité des langues. Clermont-Ferrand : Presses Universitaires Blaise Pascal. p. 7-16, 2007.

GUIMARÃES, A. S. A. Racismo e anti-racismo no Brasil. Editora 34, 1999. $\overline{2011}$. Raça, cor, cor da pele e etnia. Cadernos de Campo (São Paulo), v. 20, n. 20, p. 265-271,

HALL, S. Identités et cultures: politiques des cultural studies. Paris: Éditions Amsterdam, 2007.

LORCERIE, F. La non-lutte contre les discriminations dans l'Ecole française. Hommes \& Migrations, v. 1246, n. 1246, p. 6-16, 2003a.

LORCERIE, F. L'école et le défi ethnique: éducation et intégration. Paris : ESF éditeur, 2003b.

LUCRÈCE, A. Art et interculturalité. In FERRÈO, G; JUCQUOIS, G. Dictionnaire de l'altérité et des relations interculturelles. Paris : Armand Colin, p. 25-29, 2004.

MENESR. La refondation de l'École de la République: Climat scolaire et prévention des violences. 2015a. Disponível em: <http://www.education.gouv.fr/pid29462/la-refondation-de-1ecole-de-la-republique.html>. Acesso em: 01 abr. 2017.

Programmes d'enseignement de l'école élémentaire et du collège: BO spécial du 26 novembre 2015b. Disponível em: <http://www.education.gouv.fr/cid95812/au-bo-special-du-26novembre-2015-programmes-d-enseignement-de-l-ecole-elementaire-et-du-college.html $>$. Acesso em: 01 abr. 2017.

La Semaine d'éducation contre le racisme et l'antisémitisme. 2017a. Disponível em: <http://www.education.gouv.fr/cid66966/la-semaine-d-education-contre-le-racisme-et-lantisemitisme.html\&xtmc=racisme \&xtnp=1\&xtcr=7>. Acesso em: 01 abr. 2017

. Littérature. 2017b.

em:

<http://eduscol.education.fr/cid58816/litterature.html\#lien0>. Acesso em: 01 abr. 2017.

MOLAR, J. O. Alteridade: uma noção em construção. Trabalho apresentado no VIII Congresso Nacional de Educação (EDUCERE), Edição internacional, Ponta Grossa. 2008.

MUNANGA, K. A difícil tarefa de definir quem é negro no Brasil. Estudos avançados, v. 18, n. 50, p. 51-66, 2004.

Por que ensinar a história da África e do negro no Brasil de hoje? Revista do Instituto de Estudos Brasileiros, n. 62, p. 20-31, 2015.

NDIAYE, P. Questions de couleur. Histoire, idéologie et pratiques du colorisme. De la question sociale à la question raciale, p. 37-54, 2006.

Revista Interinstitucional Artes de Educar. Rio de Janeiro, V. 6, N.2- pág. 713-734 maio-agosto de 2020: "Bebês e crianças: cultura, linguagem e politicas" 
NIÈRES-CHEVREL, I. Introduction à la littérature de jeunesse. Paris : Didier Jeunesse, 2009.

PAYET, J. La ségrégation scolaire: une perspective sociologique sur la violence à l'école. Revue française de pédagogie, p. 21-34, 1998.

PAYET, J. LAFORGUE, Denis. Qu'est-ce qu'un acteur faible? Contributions à une sociologie morale et pragmatique de la reconnaissance In : PAYET,P ; LAFORGE, D. La voix des acteurs faibles : de l'indignité à la reconnaissance. (org). Rennes : Presses Universitaires de Rennes. p. 9-25, 2008.

POSLANIEC, C. Pratique de la littérature de jeunesse à l'école. Paris : Hachette éducation, 2003.

PRINCE, N. La littérature de jeunesse. Paris : Armand Colin, 2010.

RAIBAUD, Y. Géographie des musiques noires. Géographie et cultures (Paris), n. 76, 2010.

RODRIGUES, T. C.; ABRAMOWICZ, A. Diversidade e as políticas públicas de educação. Revista Contrapontos, v. 11, n. 3, p. 244-254, 2011.

SANTOS, R. E. (org). Diversidade, espaço e relações étnicas: O negro na geografia do Brasil. Belo Horizonte: Autêntica Editora, 2007.

SILVA, Petronilha Beatriz Gonçalves. Aprender, Ensinar. Relações Étnico-raciais no Brasil. Educação, Porto Alegre, 30, p. 489-506, 2007.

SILVA, S. A. A Presença da Literatura nas Escolas e a abordagem das questões étnico-raciais. XVIII ENCONTRO NACIONAL DE DIDÁTICA E PRÁTICA DE ENSINO - ENDIPE, 18., 2014, Fortaleza. Anais. Fortaleza: Eduece, 2014. v. 2, p. 1 - 10. Disponível em: <http://www.uece.br/endipe2014/ebooks/livro2/A\%20PRESEN\%C3\%87A\%20DA\%20LITERA TURA\%20NAS\%20ESCOLAS\%20E\%20A\%20ABORDAGEM\%20DAS\%20QUEST\%C3\%95 ES\%20\%C3\%89TNICO\%20RACIAIS.pdf>. Acesso em: 01 abr. 2017.

THIERY, Nathalie; FRANCIS, Véronique. Figures et représentations de l'enfant noir dans les albums pour la jeunesse. Spirale-Revue de recherches en éducation, v. 55, n. 55, p. 39-57, 2015.

TODOROV, Tzvetan. Nous et les Autres. La réflexion française sur la. Paris : Le Seuil, 1989.

VAN DER LINDEN, Sophie; VAN DER LINDEN, Sophie. Lire l'album. Le Puy en Velay: Atelier du poisson soluble, 2006.

\footnotetext{
i Professora-pesquisadora da Ecole Supérieure du Professorat et de l'Education, Université d'Orléans, Orléans (França). Doutora em Ciências da Educação pela Universidade Paris X Nanterre. Diretora de publicação e editora-
}

Revista Interinstitucional Artes de Educar. Rio de Janeiro, V. 6, N.2-pág. 713-734 maio-agosto de 2020: "Bebês e crianças: cultura, linguagem e políticas" 
chefe da revista Internationale d'Education Familiale. E-mail: veronique.francis@univ-orleans.fr ORCID : https://orcid.org/0000-0001-6629-8995

ii Professora-pesquisadora do Institut régional du travail social (IRTS) de Montrouge (França). Doutora em Ciências da Educação pela Universidade Paris Descartes. Laboratório CERLIS - Centre de Recherche sur les Liens Sociaux. E-mail: vaceba01@ gmail.com ORCID : https://orcid.org/0000-0001-6187-1633

Revista Interinstitucional Artes de Educar. Rio de Janeiro, V. 6, N.2- pág. 713-734 maio-agosto de 2020: "Bebês e crianças: cultura, linguagem e políticas"

DOI: 10.12957/riae.2020.48924 